\title{
BIM 技术在建筑工程施工管理中的应用解析
}

\author{
秦海港
}

中石化第十建设有限公司，山东青岛 266000

[摘要] 经济的发展, 社会的进步, 不仅促进了建筑行业的发展也给建筑工程施工管理工作提出了新的要求。再加之建筑工程 的施工量、复杂程度逐渐增加对施工技术的要求也越来越高, 因此建筑工程施工管理人员应不断强化管理工作，并跟紧时代 发展的步伐，提升管理工作的效率与质量，在此基础上提升自身企业在建筑市场中的竞争力，促进企业的长远发展。在这样 大的发展环境下 B I M 技术得到了广泛的应用,企业在进行施工管理时可以充分的利用 BIM 技术对管理方式等进行优化与完善, 充分的显现出其在施工管理中的作用，并在今后的使用中不断的进行拓展，以此来促进整体建筑行业的信息化水平，加快建 筑行业的发展。

[关键词]BIM 技术; 建筑工程; 施工管理; 应用

DOI: $10.33142 /$ sca.v2i2.338 中图分类号: TU17;TU71 文献标识码: A

\section{Application Analysis of BIM Technology in Construction Management of Construction Engineering}

QIN Haigang

Sinopec 10th construction co., Ltd., Shandong Qingdao, China 266000

\begin{abstract}
The economic development and social progress not only promote the development of the construction industry, but also put forward new requirements for the construction management of the construction project. In addition, with the construction quantity of construction project, the complexity is gradually increasing and the requirements for construction technology are getting higher and higher, so the construction management personnel of construction project should constantly strengthen the management work and keep up with the pace of the development of the times. Improve the efficiency and quality of management, on this basis, enhance the competitiveness of their own enterprises in the construction market, promote the long-term development of enterprises. In such a great development environment, BIM technology has been widely used, and enterprises can fully carry out construction management. By using the BIM technology to optimize and perfect the management mode and so on, the role of the BIM technology in the construction management is fully shown, and the development of the whole construction industry can be accelerated, and the development of the construction industry can be accelerated.
\end{abstract}

Keywords: BIM technology; Construction engineering; Construction management; Application

\section{$1 \mathrm{BIM}$ 技术的主要特点}

1.1 可视性

建筑工程属于系统性较强的工程, 其中包含的内容相对较多, 所以管理的过程也相对复杂, 也给施工质量及安全 管理工作带来一定的困难, 因此应得到管理人员的关注。传统的施工管理方式具有一定的局限性, 在进行管理时缺乏 一定的直观感、体验感, 更无法实现施工管理的科学性与有效性, 但是在 BIM 技术的帮助下可以对施工管理起到辅助 作用, 提供相应的帮助。BIM 技术充分的利用计算机作为载体, 并使用相似的软件来进行管理, 将建筑施工管理中所涉 及到的数据进行信息化绘制, 以此来快速的形成图纸, 管理人员可以通过计算机系统实现建筑施工管理可视化, 利用 所得到的三维图纸实现全方位施工管理。

1. 2 协调性

建筑工程中不同环节的工作内容与施工技术有所区别, 这样就需要做好相邻工序的连接工作, 如果出现连接不畅 的情况会给施工进度带来不利的影响, 同时施工技术衔接出现问题会导致质量问题的出现。在施工中应用 BIM 技术可 以有效的提升技术交底工作的效率，不同的部门可以通过对图纸的观察对不同施工环节所需要的技术与人员进行合理 分配。但是, 传统的图纸多以纸质材料为主, 在使用过程中会因为环境的改变而发生变化, 而 BIM 技术在计算机数据 的帮助下试实现对各个部门间的协调, 并可以在管理中构建局域网完成图纸传输工作, 保证图纸传输的准确性, 可以 提前知晓施工建设情况, 并及时的做出调整, 确保工程可以顺利进行。

1.3 模拟性

从建筑工程角度来说, 无法只通过想象对工作进行管理, 更无法对建筑工程进行试验检测, 但是通过对 BIM 技术 
的利用构建起建筑模型, 将其进行立体化展示, 更可以将传统的思维方式进行转变, 有序的开展管理工作。在建筑工 程施工管理中应用 BIM 技术可以有效的解决管理中的难题, 例如节能管理、安全管理等, 根据模拟结果的不同施工管 理人员可以采用不同的管理方式，并可以将施工过程中可能存在的隐患进行及时的调整与规避。

\section{4 优化性}

建筑工程管理工作中施工管理是其中的重点, 如果在施工中出现安全问题会给后期建设带来不利的影响, 严重的 话还会给验收人员的人身安全带来隐患。BIM 技术可以根据工程信息进行虚拟化管理, 并在计算机系统的帮助下对建筑 工程方案进行调整与优化，并将调整、优化后的结果进行及时的反馈，提升建筑施工管理的水平。

\section{2 现阶段 BIM 技术在施工管理中的应用现状}

随着信息技术的不断发展, 其也得到了不同行业的认可与应用, 并起到了推动作用。将信息化技术引入到建筑行 业中, 通过 BIM 技术进行建筑工程施工管理工作可以进一步加快建筑行业的发展, 并可以有效的解决施工管理中所显 现出的问题, 为施工质量提供保障。由于我国建筑工程中应用 BIM 技术相对较晚, 所以 BIM 技术在施工管理中还存在 一定缺陷, 管理水平相对落后, 因此 BIM 施工管理制度还在编制阶段。现阶段, BIM 技术在施工质量管理中的应用还处 于摸索阶段，应在不断应用过程中对其进行完善，以此来提升施工管理的实际效果。

随着 BIM 技术在建筑施工管理中的应用, 在一定程度上提升了施工管理的效率与质量。更多的施工企业将更多的 资金投入到 BIM 技术开发中, 在一定程度上促进了 BIM 技术在建筑行业的快速发展。但是在建筑工程施工管理中应用 BIM 技术的过程中还存在一些缺陷, 比如, BIM 技术应用过程中的相关标准、技术软件中数据的流失等, 这些问题都给 BIM 技术在建筑工程施工管理中的应用带来不利的影响。目前, 还有一部分建筑企业并没有认识到 BIM 技术在施工管理 中的作用, 没有积极的对 BIM 技术进行开发, BIM 技术的应用可以充分的展现出建筑企业的管理水平与技术水平, 因此 应重点关注研发与应用工作，充分的利用 BIM 技术解决施工管理中的问题。

\section{BIM 技术在建筑施工管理中的具体应用}

\section{1 BIM 技术在安全管理中的应用}

近些年来，各建筑企业不断加强安全管理工作的力度，但是在管理过程中并没有达到理想的效果，并没有有效的 控制安全事故的发生率, 不仅给施工人员的生命安全带来影响, 同时也影响了企业的经济效益与社会效益。传统的安 全管理模式为了对安全施工进行防范, 加强可对安全隐患的检查、排查力度, 但是结果并没有达到预期的效果。利用 BIM 技术可以根据施工安全管理的需要构建起安全管理数据模型, 安全管理人员在模型的帮助下可以提前了解工程施工 中可能遇到的安全问题，并及时的进行防范，以此来降低工程安全事故的发生，提升施工安全管理的质量与效果。

\section{2 BIM 技术在成本管理中的应用}

建筑工程施工成本管理工作主要是对材料、设备及人员等方面进行管理, 将 BIM 技术应用到施工成本管理中可以 实现对施工成本全面的、动态化管理，有效的对成本进行核算与控制等，成本管理人员可以对工程中的人员、材料、 设备等成本数据进行及时的获取、分析等，实现对施工成本的有效控制，并可以提升施工成本结算水平。

\section{3 BIM 技术在进度管理中的应用}

在编制施工计划模型时通常会使用网络横道图编制法, 但是此种编制方法存在一定的缺陷, 如果在施工进度管理 中出现问题, 企业需要对其进行重新编制, 这样在一定程度上增加了管理人员的工作量, 直接影响施工进度。利用 BIM 技术的可视化功能, 进行进度管理信息模型的构建, 模型可以在施工中通过 $4 \mathrm{D}$ 模拟图形、三维图形弥补网络横道图中 的不足, 以此对施工进度管理进行优化。

\section{4 BIM 技术在质量管理中的应用}

建筑施工管理中质量管理是其中的重点, 但是影响施工质量的因素也相对较多, 例如施工人员操作水平、材料质 量管理、施工监管工作等。传统的施工质量管理工作多以人工管理方式为主, 这样会受到人为主观因素的影响。将 BIM 技术应用到施工质量管理中可以通过模型对管理者的管理行为进行规范, 确保施工技术人员操作可以在标准的范围内 并可以提升施工质量监管水平，确保施工技术与实际施工的一致性，实现施工质量管理目标。

\section{4 结语}

通过以上内容可以了解到, 将 BIM 技术充分的融入到建筑工程施工管理工作中可以有效的提升管理工作的效率并 可以为施工质量管理提供动力。在实际的建筑工程施工过程中还存在一些弊端, 要想确保 BIM 技术在建筑施工管理中 的有效应用, 各管理部门、管理人员应正确认识 BIM 技术在施工管理中的作用, 并积极的利用 BIM 技术对施工管理工 作进行调整与优化, 以此来提升建筑企业的整体效益。

\section{[参考文献]}

[1]任国智. BIM 技术在建筑工程施工管理中的应用探索 [J]. 智能建筑与智慧城市, 2018(04): 67-68.

[2]王宝新. BIM 技术在建筑工程施工管理中的应用 [J].建材与装饰, 2018(40): 117-118.

[3] 谢磊. BIM 技术在建筑工程建设管理中的应用分析 [J]. 建材与装饰, 2018 (42) : 184-185.

作者简介: 秦海港, 男, (1987-), 本科, 工程师。 